This item was submitted to Loughborough's Research Repository by the author.

Items in Figshare are protected by copyright, with all rights reserved, unless otherwise indicated.

\title{
Cultural geographies of education
}

PLEASE CITE THE PUBLISHED VERSION

http://dx.doi.org/10.1177/1474474015612717

\section{PUBLISHER}

SAGE Publications (@ The Authors)

\section{VERSION}

AM (Accepted Manuscript)

\section{PUBLISHER STATEMENT}

This work is made available according to the conditions of the Creative Commons Attribution-NonCommercialNoDerivatives 4.0 International (CC BY-NC-ND 4.0) licence. Full details of this licence are available at: https://creativecommons.org/licenses/by-nc-nd/4.0/

\section{LICENCE}

CC BY-NC-ND 4.0

\section{REPOSITORY RECORD}

Mills, Sarah, and Peter Kraftl. 2019. "Cultural Geographies of Education". figshare. https://hdl.handle.net/2134/19936. 


\section{Guest editorial: Cultural geographies of education}

Sarah Mills and Peter Kraftl

To cite: Mills, S. and Kraftl, P. (2016) Cultural Geographies of Education, cultural geographies 23 (1): $19-27$

\section{Introduction}

Research on the geographies of education has been acknowledged as a burgeoning area of interest within the discipline ${ }^{1}$ and has recently been described as an important and relevant 'disciplinary endeavour'. ' However, the cultural geographies of education have, in general, been overshadowed by social and political-economic research on spaces and sites of education. Some of that work has touched on articulations of identity, emotion and embodiment (e.g. a special issue of Social \& Cultural Geography in 2011), but has not demonstrated engagement with a fuller range of conceptual and methodological frames more prevalent in cultural-geographic approaches. Elsewhere, and over a longer period, isolated studies have, for instance, used archival approaches to understand materialities, landscapes and performances of education ${ }^{3}$, the constitution of affects in school buildings ${ }^{4}$, and theorised 'life-itself' within alternative education spaces ${ }^{5}$. However, the above kinds of research remain relatively rare and disparate.

This special issue focuses explicitly upon, and seeks to bring together, diverse cultural geographies of education. It aims to bring into dialogue both cultural and/or historical geographers who already position themselves within this field and/or within children's geographies and, importantly, cultural geographers whose work is related to ideas about learning, education, governance or moral geographies who we felt could shed new light on existing ideas through key concepts and theories within cultural geography. Inspired by Chris Philo's keynote paper presented at the $2^{\text {nd }}$ International Conference on the Geographies of Education held at Loughborough University in September 2012, we then invited a series of authors (from both the conference and outside that forum) to respond to an invitation to consider the 'cultural geographies of education' most broadly understood. Rather than framing the special issue around a particular learning site (i.e. the school or the 'great outdoors'), we instead encouraged authors to use cultural geography as an entry point to push at what a cultural perspective might bring to the geographies of education. In so doing, the special issue aims to constitute a series of new and fresh approaches to work on geographies of education, opening up and exemplifying fruitful avenues for future research. In this editorial introduction, we map out these potential avenues and provide a discursive commentary that both introduces the collection whilst also asking some more provocative questions about this scholarship and related debates.

\section{Cultures of education / educational cultures: towards new languages for the geographies of education?}

The papers in this special issue draw upon both historical and contemporary examples of formal, nonformal and informal educational settings. ${ }^{6}$ All of the authors focus on learning processes, politics and praxes to consider what is actually happening within these spaces: be that engagements with nature, 
landscape, material objects, digital data or other bodies. In so doing, the papers examine learning spaces and practices around a wide range of topics: music, yoga, a national educational curriculum, how to contest 'illegality', how to be a 'good' citizen, how to be a 'better' worker, or how to be 'human'. But more than simply offering this empirical diversity and breadth, these papers offer a new set of vocabularies for the geographies of education: of progress, optimism/optimisation, authority, habit, training, dispossession and 'wildness' - that can be used to examine cultures of education and educational cultures. We therefore see the central contribution of this special issue as offering these substantively different and important new sets of languages, highlighted in the following brief paper summaries.

Matt Finn's paper provides a theoretically-informed account of the changing cultures of education in English state schools through their use of data to monitor progress. He outlines how one school strived to maintain an 'atmosphere of progress' through drawing upon pupils' past, present and future selves, which subsequently fostered a series of emotional and affective encounters. The role of affect and emotion underlies Jessica Pykett and Bryony Enright's contribution, which traces the emergence of positive psychology-based workplace training programmes and how these promote a culture of optimism and optimisation. In analysing the emotional and psychological governance of 'brain culture', the paper asks some more critical questions of workplaces as spaces of education and of workplace training programmes as pedagogic sites for the "re-education of 'neurocitizens'”. Their discussion dovetails with a range of new approaches about emotional intelligence and flexible learning, as does Jennifer Lea et al.'s paper on themes surrounding therapeutic spaces. Here, the authors use the example of Ashtanga yoga to call for a more 'distributed' sense of authority that takes account of how an educator's authority "meshes (and sometimes conflicts with) the 'experiential authority' of the subjects being educated, articulating with their own 'self-authority'. Themes of embodied knowledge and practice also appear in Douglas Lonie and Luke Dickens' paper on music learning environments. In relation to these new emerging vocabularies, the authors propose the notion of musical habit(u)s to understand the way that young people 'become' musicians as part of the paper's wider discussion on the boundaries between formal, non-formal and informal education. Indeed, the role of embodied habits - which has become something of a point of articulation for recent cultural geographies ${ }^{7}$ - works implicitly through several other papers in this collection too (notably Finn and Lea et al.).

Sarah Mills' paper outlines the analytical purchase of a language of 'training' within the geographies of education. Her paper focuses on the cultural-historical geographies of the Woodcraft Folk - a British youth movement that she argues enrolled adults (parents and volunteers) into its wider educational remit, as well as young people. Her archival research highlights how the Folk was a complex assemblage of learners, spaces and practices that whilst firmly political in its aims, held education as its central ambition and purpose. The wider politics of education are powerfully exposed in Caitlin Cahill et al.'s paper that draws on participatory action research with young people and their families in Salt Lake City, Utah to unpack the politics of neoliberal immigration and education policies. Through the frame of 'dispossession', Cahill et al. demonstrate how these complex politics manifest themselves through the racialized exclusion that some young people experience through access to education and their imagined (educational) futures, infused with a wider atmosphere of insecurity. Finally, Chris Philo's rich and nuanced historical geography of 'idiot' education sketches out comparative models of 'educating the uneducable' through different encounters with 'wildness', landscape and architecture. His paper charts 
the role of educative-training by experts who proposed 'idiot schools' in the late $19^{\text {th }}$ century to ask broader questions about learning, re-learning and learning anew.

From the contemporary use of digital technologies and data to monitor 'progress' (Finn) to earlier forms of scientific knowledge used to shape 'educative-training' (Philo), these papers examine the production and circulation of educational cultures and cultures of education. We now move on to discuss some broader thematic ideas expressed within this collection, which both develop and extend away from social and political-economic research on spaces and sites of education.

\section{Cultures of representation / cultural politics}

Whilst several papers draw on nonrepresentational frames such as affect and habit, it is notable that they also explicitly engage with ideas about representational and cultural politics. This move is, in itself, a key contribution, since it tethers contemporary scholarship in the geographies of education to longerstanding interest in cultural geographies with the politics of representation ${ }^{8}$. Of particular note is that, taken as a whole, the papers cast new light on rather more familiar themes in (social-)geographical themes in educational research: exclusion, marginalisation and social difference ${ }^{9}$. Strikingly, several of the contributions offer illuminating analyses of how exclusion, dispossession and the marking of difference occur through cultural practices, spaces and policies.

In Caitlin Cahill et al.'s paper, cultural norms and politics that are often hidden - in this case surrounding race - become exposed through a focus on education. The authors demonstrate how processes of marginalisation operate through culture, whereby the racial politics of the 'school to sweatshop pipeline'are understood through the 'double knot of dispossession' in "how "illegality" is produced and policed in educational settings that are already sites of racialized exclusion". Overall, the paper highlights how everyday interactions are inflected via the wider cultural landscape. Similar themes can be seen in Matt Finn's discussion of 'school culture' within his study of a school in Northern England. Here, much more than school 'ethos' - "too easily imagined as collective but free-floating from socio-material and historical circumstances", he suggests that we consider something that is "more fragile, more fleeting and operates in 'pockets' or spheres which emerge and envelop members of the school in some classes and not others" (ibid). These atmospheres shape a wider cultural politics that bubbles away underneath the surface of everyday life at the school. For example, through the presence of a poster outside the school canteen that displays the academic progress of students in concentric circles, with some names appearing in the 'danger' zone of skulls and crossbones. This visible 'marker' in the school landscape creates tensions, not least as Finn notes for working-class youth. Despite the very different historical and geographical contexts, there are also striking parallels between Finn's paper and Chris Philo's - not least in their shared deployment of 'affective atmospheres' in their analyses. For, they both articulate how the modulation of bodies and affects occurs through the cultivation of shared assumptions: through the culture (or ethos) of a twenty-first century, 'data-rich school'; or through the cultural politics of the nineteenth-century 'institution'.

Lonie and Dickens' paper also demonstrates how larger-scaled (national) cultural policies - in this case surrounding the complex relationship between music and social inclusion - are played out within institutional spaces. The authors demonstrate how cultural policy is inflected through the space of the school music classroom and via the everyday, restrictive politics of young people's access to instruments. These ideas of exclusion are tinged with class-based stereotypes; although the authors do not go as far as 
explicitly discussing class, they refer to 'cultural identities' and suggest a series of judgments that are made by adult experts about young people and their behaviour. Across these papers then, cultural politics infuses with the geographies of social difference, demonstrating how exclusion works in and through educational spaces. For the authors in this collection, cultures of representation - and the representation of different identity groups - are powerful ideological devices, but also shape the everyday lived experiences of those diverse social groups.

\section{Beyond childhood and youth, beyond 'age'? Re-thinking the 'educator' and 'educated'}

Age is often used as a marker to delineate the institutional geographies of educational spaces, for example to denote movement between classes within school or the sections of a youth movement. It is also well-established that the majority of research going on under the banner of 'geographies of education' focuses on spaces and practices dedicated to children, young people and (to a lesser extent) young adults ${ }^{10}$. And yet, some of the papers in this special issue attempt to go beyond age-specific studies to re-think the assumed roles of 'educator' (as adult) and educated (as child). They also question the very teleology of 'education' and the assumption that all human subjects are, in fact, 'educable'.

Several of the settings discussed here cut across age; in fact, in several papers, age is - strikingly - not mentioned as a frame for analysis. For example, Lea et al.'s study of Ashtanga yoga and Pykett and Enright's research on workplace cultures of learning and emotional literacy are both concerned with adults. Yet - and this is far from a critique - it is not clear whether some of the participants concerned may, in fact, be 'young' (whether young adults or under 18), since it is quite possible that young people could be present in both contexts. Indeed, in both papers, we might legitimately ask to what extent it matters whether the subjects to hand are 'younger' or 'older'.

Indeed, rather than focusing on the realm of the 'adult' and the 'child', several of the papers consider instead the shifting category of 'learner', suggesting how age perhaps recedes in importance. This leads us to consider more diffuse geographies of authority and power that subsequently reform roles and relationships that may be assumed as 'fixed' (i.e. teacher, educator or expert). This theme can also be seen in Finn's paper where the 'classic' relationship of teacher and pupil is problematized through new cultures of peer-sharing of grades and progress between pupils. Indeed, these new cultures of sharing are only possible because of this new cultural (educational) context. Yet, recursively, age is important in this context: it is only because these young people are under 18, and in school, that it is possible to publicise the children's names and their educational progress on noticeboards in the schools' corridors. In UK Higher Education contexts, for instance, the publication of exam results is always anonymised, in part to protect the personal data of 'adults'.

Meanwhile, age is recast (although not necessarily effaced) in Sarah Mills' paper. We also see ideas of more complicated educator-educated relationships in Mills' paper where, in some cases, young people were cast as 'adult' volunteers and enfolded into the institutional apparatus of the Woodcraft Folk. In so doing, her analyses recalls classic studies of intergenerationality that offer more nuanced understandings of the interdependent relationships that see the relative positioning, authority and power of adults and children shifting over time and space ${ }^{11}$. Despite Finn and Mills' case-studies being at opposite ends of the political spectrum (the contemporary neoliberal school and the left-wing radical youth movement of the early twentieth century) we can see how new cultures (of education) can emerge through everyday practices, as well as re-imagined ideas of community or family. 
More broadly, the papers in this special issue have much to say about the production of the self and subjectivity. As we argue above, these processes recast or even exceed age-based categories as other identities are foregrounded. Sometimes these identities are named: broadly, as 'educator' or 'educated'; more specifically, for example, in 'worker' subjectivities (Pykett and Enright) or for identified 'musicians' (Lonie \& Dickens). Yet in a provocative departure from the other papers within this special issue that assume education is happening (often as a smooth, uninterrupted and natural process), Philo's contribution prompts us to reflect on what happens when a subject is considered 'uneducable'. Whilst we may be familiar with some contemporary frames of reference of 'at risk' young people or 'NEETs' ${ }^{12}$ who are perceived as lacking the emotional or aspirational capacity to 'progress', Philo's figure of the 'uneducable' challenges us to consider a different type of subject. Whilst the paper discusses the named 'savage of Aveyron' as the wild-child 'idiot' boy, for us the paper encourages the reader to imagine a moment or space where education might not or cannot happen. Philo's paper raises a number of questions for (cultural) geographies of education that are as profound as they are uncomfortable. For instance: what happens if there is a challenge, a barrier, an interruption or a break in the process of 'educating' in a space where education is meant to happen? Who (or what) is educable, and who (or what) is not - and in what ways should (cultural) geographers respond, conceptually, ethically and politically? On the one hand, we suggest, the figure of the 'uneducable' - not only the boy, but all that he signifies - might be a useful counterbalance or foil for the assumptions that geographers make about the spaces of education. In other words, this figure might compel us to pause, and to critically reflect, on what is meant by 'education' in the 'geographies of education'. Such a move might require deeper conversation with longer-standing philosophies of education; yet, given the ways in which - as Philo so deftly demonstrates - the figure of the uneducable is imbricated with questions of landscape, architecture and the cultural politics of institutional spaces, we would suggest that cultural geographers would afford unique perspectives on such questions. On the other hand, the figure of the uneducable as idea, space, body or energetic force - might be cause for creative, perhaps radical forms of optimism. It might offer a (conceptual and political) springboard from which to imagine moments or spaces in which radically new, hopeful, even utopian cultural forms might be imagined. The figure of the uneducable may be fleeting, but may operate as a kind of extraordinary, momentary interruption in the everyday in which alternative (con)figurations of learning, educating and simply life-itself might be imagined $^{13}$. This - tentative - observation leads us into a final set of reflections around the cultural geographies of 'mainstream' and 'alternative' education practices.

\section{Neoliberalism and the cultural geographies of mainstream and alternative education}

A third thematic idea underlying several of the papers in this collection is the status of neoliberalism and the relationship between the (increasingly neoliberalising) mainstream and alternative education sectors. On the one hand, the wider politics of neoliberalism have clearly influenced the space of the school ${ }^{14}$ (Cahill et al.; Finn) and the promotion of 'lifelong learning' in the workplace (Pykett \& Enright). On the other hand, we see how neoliberalism is consciously or unconsciously being resisted, through acts of sharing (and caring) by pupils in Finn's study or in the wider framing of yoga in Lea et al.'s paper as a resistive practice against capitalism. Furthermore, we can ask whether the cultivation of 'alternatives' to mainstream and especially State-led modes of educating are as new as they seem. In both Philo and Mills' papers, we see attempts to create 'alternative' spaces from the nineteenth and mid-twentieth centuries respectively: an alternative 'idiot' school and an alternative left-wing youth movement ${ }^{15}$. And yet, we 
witness how more 'mainstream' ideas seep into these spaces, for example Mills' discussion of competitiveness and monitoring techniques within the Woodcraft Folk. Here, despite attempts to offer an alternative and radical departure from the conservative and popular Boy Scouts, and the pedagogy of formal education, the Folk still constructed a mirroring institutional apparatus to structure their educational programme - one of record cards, examinations and badges. This poses questions about the emergence and practices of mainstream and alternative educational spaces - spaces that do not exist in isolation, but rather operate within a wider landscape of educational praxis and in relation to one another.

These reflections prompt us to consider: can work on the cultural geographies of education reflect back upon neoliberalism itself? Does it exceed and challenge ideas of what is alternative and mainstream through re-thinking cultural political economies? What kind of relationships exist between neoliberalism and education that go beyond neoliberal educational policies? ${ }^{16}$ Certainly, these culturalhistorical perspectives are vital to better-understanding contemporary currents in education around the world. Alternative education spaces are gaining traction in diverse geographical contexts, and offer both a range of challenges and opportunities to more conventional, State-led provision - from the Free Schools movement in the UK to proposals in stronger social-democratic states (like Finland) to sanction, for the first time, privatised, elite schools ${ }^{17}$. Yet research - in geography and elsewhere - is currently lagging behind these developments, and it is our contention that the languages developed in the papers in this special issue might afford critical and constructive points of engagement. This is, not least, because many of the contributions are situated in spaces called 'schools'. In fact, they offer analyses that either straddle the 'mainstream', 'alternative' and 'informal' sectors, or which highlight the relatedness of different realms in, for instance, what Cahill et al. term the 'school-to-sweatshop pipeline'.

\section{Cultural geographies of technology, knowledge and education}

Cultural geographers have exhibited a longstanding interest in the twin roles of technology and knowledge in the production and experience of cultural spaces. Historical geographers have, for instance, examined how the development of geographical knowledge has articulated with cultures and histories of exploration, colonialism and landscape ${ }^{18}$. Indeed, some of that work has explicitly reflected upon the relationship between contemporary understandings of geographical processes and (schoolbased) education ${ }^{19}$. More recently, cultural geographers have questioned the boundaries between human and nonhuman, offering critical insights into the governance of life-itself through diverse knowledges and technologies of rule ${ }^{20}$.

The articles in this special issue do not necessarily draw on the conceptual frames listed above (although some touch on them). Rather, they offer a series of novel starting points for thinking through the elision of technology, knowledge and education in different historical, geographical and cultural contexts. As we have already indicated, several of the papers reflect on the 'technologies' of power and rule that seek to govern subjectivities in contemporary education settings. Most notably, Matt Finn's paper observes how contemporary digital technologies - which enable the manipulation, interrogation and visualisation of 'big' datasets - are an integral part of the production of cultures of aspiration and shame in the classrooms and corridors of a school. Two papers - by Pykett and Enright, and Philo - offer important new insights into the role of 'scientific' knowledges and technologies as they are manifest in education settings. Pykett and Enright demonstrate how cultures of optimism and optimisation rely on (highly 
contested) interpretations of contemporary brain science in the workplace. Meanwhile, Philo offers an analysis of how the 'uneducable' figure of the wild boy of Aveyron constituted a challenge to contemporary scientific understandings - and treatments - of child development. As we have already discussed, the other papers offer broader challenges to the status of 'expert' or 'scientific' knowledges through more distributed senses of authority (Lea et al.), through the intergenerational co-production of volunteering (Mills) and through attempts to exceed or subvert pervasive (and divisive) logics of contemporary governance (Lonie and Dickens; Cahill et al.).

In doing the above, the papers in this special issue demonstrate how technology, knowledge and education are entangled and negotiated in diverse educational spaces. Moreover, through their empirical analyses, they show how these three are entwined in the production of cultural forms, identities, practices and spaces. It is our contention, however, that geographers of education have, aside from a few exceptions, not subjected the triad of technology-knowledge-education to sufficient scrutiny. There remains considerable scope, for instance, to take Matt Finn's lead in critically examining how digital technologies are co-constituting contemporary educational spaces, questioning whether and how they are challenging or simply reinforcing existing socio-cultural norms and divides. Elsewhere, geographers might follow Pykett and Enright in studying how, in different contexts, cutting-edge scientific knowledges are being deployed in educational institutions, scrutinising the cultivation of biopolitical subjects. Some of the papers in this special issue also offer a timely reminder that we must redouble our efforts to examine the striking resonances and dissonances between technologyknowledge-education in the past and present eras. In these and other possibilities for future work, cultural-geographical frames of reference - of materiality, affect, embodiment, representation and built form - should surely have an important place. Thus, the papers in this special issue offer a range of novel conceptual languages and empirical analyses that might inspire further work, on as-yetunresearched and pressing issues, in the geographies of education.

\section{Conclusion}

Our hope is that this special issue offers some provocative ways of (re)thinking the geographies of education, using cultural geography as an entry point. We are open to other ways of 'doing' the geographies of education and this editorial is not meant to 'fix' the new vocabularies suggested by these seven papers as 'the way' that cultural geography might animate or spark new directions in disciplinary work on education, but rather we hope it will be the beginning of a conversation. These papers offer a useful point of departure - and a series of critical questions - for future lines of enquiry to be drawn and for other vocabularies to emerge. These may further blur the boundaries between the formal and informal, the educator and the educated, the mainstream and the alternative, so that the wider cultural politics - and cultural geographies - of education in all its diverse forms can be further interrogated, exposed and challenged.

\section{Biographical Notes}

Sarah Mills is Senior Lecturer in Human Geography at Loughborough University

Peter Kraftl is Professor of Human Geography at the University of Birmingham 


\section{Acknowledgments}

We wish to extend our thanks to all the authors for their contributions and critical engagement with the theme of this collection. Thanks to the organisers of the $2^{\text {nd }}$ International Conference on the Geographies of Education held at the Department of Geography, Loughborough University in September 2012 and their encouragement to pursue this special issue. Thanks also to Tim Cresswell, Dydia DeLyser and John Wylie for their editorial guidance and support.

${ }^{1}$ C. Hanson Thiem, 'Thinking through education: the geographies of contemporary educational restructuring', Progress in Human Geography, 33 (2), 2009, pp.154-173; S. L. Holloway, P. Hubbard, H. Jöns and H. Pimlott-Wilson, 'Geographies of education and the significance of children, youth and families', Progress in Human Geography 34 (5), 2010, pp.583-600

${ }^{2}$ S. L. Holloway and H. Jöns, 'Geographies of education and learning', Transactions of the Institute of British Geographers 37 (4), 2012, 482-488.

${ }^{3}$ P. Gruffudd, 'The countryside as educator: schools, rurality and citizenship in inter-war Wales', Journal of Historical Geography 22 (4), 1996, pp.412-423; T. Ploszajska, 'Constructing the subject: geographical models in English schools, 18701944’, Journal of Historical Geography 22 (4), 1996, pp.388-398; E. A. Gagen, 'Making America flesh: physicality and nationhood in early twentieth century physical education reform', Cultural Geographies 11 (4), 2004, pp.417-442; S. Mills, “'An Instruction in Good Citizenship": Scouting and the Historical Geographies of Citizenship Education', Transactions of the Institute of British Geographers, 38, 2013, 120-134

${ }^{4}$ For example, P. Kraftl, 'Building an idea: the material construction of an ideal childhood', Transactions of the Institute of British Geographers 31 (4),2006, 488-504; P. Kraftl 'Utopian promise or burdensome responsibility? A critical analysis of the UK government's building schools for the future policy', Antipode 44 (3), 2012, 847-870

${ }^{5}$ P. Kraftl Geographies of Alternative Education: Diverse Learning Spaces for Children and Young People (Bristol: Policy Press, 2013)

${ }^{6}$ On these definitions and debates, see S. Mills and P. Kraftl, Informal Education, Childhood and Youth: Geographies, Histories, Practices (Basingstoke, UK: Palgrave Macmillan, 2014)

${ }^{7}$ See, for instance, a recent special issue of Cultural Geographies on habit, and an instructive editorial introduction: J.D. Dewsbury and D. Bissell, 'Habit geographies: the perilous zones in the life of the individual', Cultural Geographies, 22(1), 2015, 21-28.

${ }^{8}$ See, for instance, T. Barnes and J. Duncan, Writing Worlds: Discourse, Text and Metaphor in the Representation of Landscape (London: Routledge, 1992).

${ }^{9}$ See, for instance: R. Johnston, S. Burgess, R. Harris, R. and D. Wilson, 'Sleep-walking towards segregation'? The changing ethnic composition of English schools, 1997-2003: an entry cohort analysis' Transactions of the Institute of British Geographers, 33, 2008, 73-90.

${ }^{10}$ Indeed, there is a close relationship between social geographies of education and subdisciplinary children's geographies - a point exemplified by Holloway et al., 'Geographies of education'.

${ }^{11}$ S. Punch, 'Youth transitions and interdependent adult-child relations in rural Bolivia', Journal of Rural Studies, 18(2), 2002, 123-133.

${ }^{12}$ NEET refers to young people 'Not in Education, Employment or Training'

${ }^{13}$ This tentative observation resonates with a constellation of ideas around the eruption of utopian moments in everyday life, and their potential for enduring forms of alterity that challenge the status quo. See, for instance, M. Gardiner, 'Everyday utopianism: Lefebvre and his critics', Cultural Studies, 18(2-3), 2004, 228-254; L. Garforth, 'No intentions? Utopian theory after the future'. Journal for Cultural Research, 13(1), 2009, 5-27; M. Hardt, and A. Negri, 2009, Empire (Boston: Harvard University Press); P. Kraftl, 'Alter-childhoods: Biopolitics and childhoods in alternative education spaces', Annals of the Association of American Geographers, 105, 2015, 219-237.

${ }^{14}$ A wider point taken up and contested by Hanson Thiem, 'Thinking through education'.

${ }^{15}$ Federico Ferretti's work is exemplary in this regard, as it traces the 'alternative' educational philosophies of a number of Francophone theorists from the nineteenth century onwards. See, for instance, F. "'They have the right to throw us out”: Élisée Reclus' New Universal Geography', Antipode, 45(5), 2013, 1337-1355.

${ }^{16}$ On these debates, see S. L. Holloway and H. Pimlott-Wilson, 'Neoliberalism, policy localisation and idealised subjects: a case study on educational restructuring in England', Transactions of the Institute of British Geographers, 37(4), 2012, 639-654

${ }^{17}$ For a more detailed overview, see Kraftl, 'Geographies of Alternative Education',

${ }^{18}$ For example, see: D. Livingstone, The Geographical Tradition: Episodes in the History of a Contested Enterprise (Oxford: WileyBlackwell, 1993); F. Driver, 'Geography's empire: histories of geographical knowledge', Environment and Planning D: Society and Space, 10(1), 1992, 23-40. 
${ }^{19}$ See, for instance: A. Maddrell, 'Empire, emigration and school geography: changing discourses of imperial citizenship, 1880-1925', Journal of Historical Geography 22 (4), 1996, pp.373-387; T. Ploszajska, 'Moral landscapes and manipulated spaces: gender, class and space in Victorian reformatory schools', Journal of Historical Geography 20 (4), 1994, pp.413-429 ${ }^{20}$ See, for instance: B. Braun, 2007, 'Biopolitics and the molecularization of life', Cultural Geographies, 14(1), 6-28; S.

Hinchliffe and N. Bingham, 'Securing life: the emerging practices of biosecurity', Environment and Planning A, 40(7), 2008, 1534-1551. 